\title{
Lessons Learned from Developing a Patient Engagement Panel: An OCHIN Report
}

\author{
Jill Arkind, MPH, Sonja Likumabuwa-Ackman, MID, MPH, Nate Warren, MPH, \\ Kay Dickerson, BA, Lynn Robbins, BA, Katby Norman, BS, and \\ Jennifer E. DeVoe, MD, DPhil
}

There is renewed interest in patient engagement in clinical and research settings, creating a need for documenting and publishing lessons learned from efforts to meaningfully engage patients. This article describes early lessons learned from the development of OCHIN's Patient Engagement Panel (PEP). OCHIN supports a national network of more than 300 community health centers (CHCs) and other primary care settings that serve over 1.5 million patients annually across nearly 20 states. The PEP was conceived in 2009 to harness the CHC tradition of patient engagement in this new era of patient-centered outcomes research and to ensure that patients were engaged throughout the life cycle of our research projects, from conception to dissemination. Developed by clinicians and researchers within our practice-based research network, recruitment of patients to serve as PEP members began in early 2012. The PEP currently has a membership of 18 patients from 3 states. Over the past 24 months, the PEP has been involved with 12 projects. We describe developing the PEP and challenges and lessons learned (eg, recruitment, funding model, creating value for patient partners, compensation). These lessons learned are relevant not only for research but also for patient engagement in quality improvement efforts and other clinical initiatives. (J Am Board Fam Med 2015;28:632-638.)

Keywords: Patient-Centered Outcomes Research; Patient Engagement; Populations, Underserved; Primary Health Care

Patient engagement strategies are increasing across health care settings in response to the recognized need to more actively include patients' voices in

This article was externally peer reviewed.

Submitted 6 January 2015; revised 23 March 2015; accepted 13 April 2015.

From OCHIN, Portland, OR (JA, NW, JED); Department of Family Medicine, Oregon Health \& Science University, Portland (SL-A, JED); and the OCHIN Patient Engagement Panel (KD, Portland, Oregon; LR, Eureka, California; KN, Enterprise, Oregon).

Funding: This work was financially supported by the $\mathrm{Na}$ tional Institutes of Health National Library of Medicine (grant no. RC4 1001482); the Patient-Centered Outcomes Research Institute (PCORI), PFA Cycle I Contract (2012), Health Systems; the Health Resources and Services Administration (grant no. UB2HA20235); and the Oregon Health \& Science University Department of Family Medicine. This work was also supported through a Patient-Centered Outcomes Research Institute (PCORI) Award (CDRN-1306-04716) for development of the National Patient-Centered Clinical Research Network, known as PCORnet. The statements presented in this article are solely the responsibility of the authors and do not necessarily represent the views of the Patient-Centered Outcomes Research Institute (PCORI), its Board of Governors or Methodology Committee or other participants in PCORnet. decisions made within the health care system. In clinical settings patients are being recruited to serve on advisory panels and as evaluators of quality improvement projects—allowing patients to be more active participants in their own health care. ${ }^{1}$ In research settings patients have traditionally been engaged through advocacy groups with an interest in specific conditions (eg, the American Heart Association, the American Diabetes Association). ${ }^{2}$ The Patient-Centered Outcomes Research Institute (PCORI) has also recently created several patient-powered research networks, which are using a similar specific disease model. ${ }^{3}$ Modes of community participation often are used in communitydriven public health research; however, this often partners academics with community-based advo-

Conflict of interest: none declared.

Corresponding author: Nate Warren, MPH, Research Department, OCHIN, 1881 SW Naito Parkway, Portland, OR 97201 (E-mail: warrenn@ochin.org). 
cacy organizations and has not traditionally focused on explicitly engaging patients from within the health care settings where research and quality improvement projects are being conducted. ${ }^{2,4-10}$ Practice-based research networks (PBRNs) are stakeholder-centered organizations with an emphasis on engaging community-based clinicians ${ }^{11,12}$ and have explored using community-based participatory research strategies to engage communities and patients in primary care research settings. ${ }^{10}$ Most examples of engagement remain project-focused, however, which limits involvement to singular, discrete scopes of work and prevents patients from participating in activities that span both research projects and the research timeline. ${ }^{9,13,14}$

Although engaging stakeholders in research and clinical activities is not a new concept, recent efforts by PCORI and others to necessitate meaningful engagement require better ways of defining and measuring patient engagement. ${ }^{15}$ This renewed interest has led to an increasing number of excellent reviews and conceptual frameworks that have developed shared terminology and common definitions to identify categories of stakeholders, to delineate the roles stakeholders play, and to capture the unique experiences that inform research. ${ }^{16-19}$ We describe early lessons learned in developing a patient engagement panel (PEP) for research.

\section{Brief Background Regarding OCHIN and the PEP}

Founded in 2001, OCHIN is a nonprofit, community-based health information technology collaborative based in Portland, Oregon. Originally called the Oregon Community Health Information Network, it is now referred to as "OCHIN" because it serves $>300$ community health centers (CHCs) in 19 states, with more than 3000 providers caring for $>1,500,000$ patients. $^{20-22}$ As of March 2015, OCHIN's research portfolio included 22 active projects, including comparative effectiveness, dissemination and implementation, informatics, public health, and health services research. CHCs, the majority of OCHIN's membership, have a long history of empowering and engaging patients on their community-based governing boards. ${ }^{23}$ While OCHIN researchers had developed mechanisms for engaging patients and communities in specific research projects ${ }^{24}$ (eg, community retreats, focus groups, patient interviews, and project advisory councils), we had not explicitly structured research governance in a way that enabled direct patient engagement in all aspects of the work longitudinally. The OCHIN PEP was conceived in 2009 to harness the $\mathrm{CHC}$ tradition of patient engagement in this new era of patient-centered outcomes research. Over the following 6 years, the progression of the PEP from concept to practice had both barriers and important discoveries.

\section{Challenges and Lessons Learned}

\section{Recruiting a Diverse, Representative Patient Sample}

We continue to face the challenge of recruiting PEP members representative of a range of different backgrounds or hard-to-reach groups. ${ }^{2,13,25}$ Federally qualified health center patient and community boards have also reported struggling to represent the homeless, the single parent, the less-educated, the disabled, and patients living in poverty. ${ }^{1}$ Our major barriers included finding people who were interested in participating in this unfamiliar undertaking and ensuring that those who did express interest were able to join despite logistic or geographical barriers.

\section{Lessons Learned}

In the beginning, we limited the PEP membership to English-speakers who were competent using technology (E-mail, computer, remote meeting software) and were available during weekday meeting times. We learned that patients who self-select to participate in this kind of endeavor are not "average" patients and come with drive and direction, which provided necessary momentum. The founding PEP members are now leading the PEP and help to recruit members and foster a collaborative, supportive environment. Over the past 2 years, the PEP has been involved with 12 projects as advisors and patient experts. The most active members serve as patient co-investigators on several projects, ${ }^{26}$ present at national conferences, and help develop research proposals and manuscripts. ${ }^{27}$

We created a brief, lay-language description of the expected role, time commitment, and potential benefits (Appendix 1) for potential PEP members. In the second year of PEP recruitment we focused on diversifying the PEP with guidance from our founding members (eg, improving the recruitment materials, identifying recruitment outlets). The 18 current PEP members now represent 3 states; 
meetings are held on a regular weekday evening to increase participation opportunities (acknowledging shifting schedules, this meeting time is frequently reviewed to ensure it still works for the majority of the group), and we offer food and travel compensation to members who join in person. We have loaned a laptop computer to 3 members and a purchased a cell phone-compatible headset for 2 others to help ease the difficulties of participating in conference calls. While the PEP members have become more diverse in age and geographic dispersion, the group is still aspiring to be even more representative of the OCHIN patient population as it matures.

\section{Creating a Sustainable Funding Structure}

Building a sustainable funding structure for the PEP has been a challenge, especially as the scope of the PEP moves beyond research projects. We found that federally funded research grants did not allow costs that were necessary to PEP members, such as parking, reimbursement for phone calls, and training opportunities.

\section{Lessons Learned}

We started out using research grants and were also able to leverage infrastructure development grants from the Health Resources and Services Administration, the National Institutes of Health, and PCORI to fund the PEP. OCHIN as an organization has prioritized this work and hired a full-time patient engagement coordinator $(\mathrm{NW})$, who oversees a modest budget. This role has primarily been funded by an infrastructure grant and provides oversight for all patient engagement activities, from research-specific (defining the scope of the patient role in a research project, identifying patients interested in the content area who are willing to serve in an official capacity) to organizational policy development (coordinating workgroups to support patient engagement strategies in CHCs, negotiating reimbursement with funders). Further opportunities for funding this work may include private nonprofits with more diverse funding initiatives and budgeting this work in future traditional research proposals that explicitly incorporate patient engagement. We have also discussed holding PEP fundraisers or creating an endowment for the PEP. As a learning organization, we realize that evaluation is critical to the continued success of an initiative such as the PEP; starting in 2015, we will be evaluating both process and outcome measures and are confident that demonstrating success will help with securing funding.

\section{Creating Added Value for PEP Members}

Initially, we felt that researchers were gaining more from the PEP than the patients. To overcome this, we had a philosophy that there needed to be added value for PEP members.

\section{Lessons Learned}

After making the decision to start a PEP, we felt it was very important to engage patients in the establishment of the group. While the PBRN and OCHIN leadership envisioned the role of the PEP, this progressed further once our founding patient members were recruited. The members participated in discussions outlining the role the PEP would play in research question development, study design, and dissemination. We currently use the following role description: "The PEP gives patients a way to actively advise and guide decision makers, providers, and researchers in work to improve patients' health care experiences and treatment options. Patient PEP members are sought out to serve in an advisory capacity on grant proposal development, patient recruitment models, tool development, project communication, changes to clinic workflows, and dissemination for patient populations."

PEP members are encouraged to pursue continuing education opportunities, including research-specific training by local organizations, conferences relevant to their research interests, and institutional review board trainings (enabling patients to be added to institutional review board protocols as co-investigators and study staff). In addition, members are also encouraged to participate in dissemination activities by having the opportunity to present findings at research conferences, annual meetings, and webinars. A "Research 101 " curriculum is being developed at OCHIN to serve as an orientation and learning opportunity for current and future PEP members.

\section{Being Equitable and Transparent With Compensation}

A major challenge was establishing a compensation mechanism. We originally envisioned compensating members with a generous hourly rate of their time, akin to the compensation model for consul- 
tants on grant-funded research studies. During discussions with PEP members, several barriers to our planned approach were raised. Many CHC patients are low-income individuals and depend on social services with income qualifications. If PEP members were paid in this way, the extra income might disqualify them for needed services.

\section{Lessons Learned}

Working in partnership with PEP members, we moved to a different compensation model, which is based on the idea that compensation must be equitable and transparent but does not need to be the same for everyone. PEP members reported that they were happy to volunteer their time, interested in opportunities to attend and present at research conferences, and said they would welcome receiving a token of appreciation (eg, gift card, travel reimbursement, donation on their behalf to a charity). We now work with PEP members to determine a customized compensation model.

\section{Conclusions}

OCHIN's PEP demonstrates the feasibility of incorporating a patient voice throughout the research life cycle, with opportunities to amplify it in additional non-research initiatives. A multistep, collaborative process was successfully used to identify and recruit patients, develop a shared vision, and agree on equitable compensation models. Many of the lessons learned through this work are transferrable to quality improvement and innovations in health care settings that would benefit from patient involvement.

We started small with a phased approach and are now recruiting a more diverse panel by offering expanded meeting time options, research training opportunities, and technology assistance. We are exploring alternative funding models and creating a tailored compensation model based on individual members' needs. We recognize that the patients who choose to participate in this work are likely to be more engaged in their health care. Therefore, these findings may be limited to similar, activated patient populations. Further research in the area of engagement of patients using a larger, populationwide level is needed.

The authors gratefully acknowledge the OCHIN PBRN and PEP members who contributed to this project.

\section{References}

1. Wright B. Do patients have a voice? The social stratification of health center governing boards. Health Expect 2013;18:430-7.

2. Boote J, Baird W, Beecroft C. Public involvement at the design stage of primary health research: a narrative review of case examples. Health Policy 2010;95: 10-23.

3. PCORnet. Patient-powered research networks. Available from: http://www.pcornet.org/patient-poweredresearch-networks/. Accessed July 21, 2015.

4. Wright D, Corner J, Hopkinson J, Foster C. Listening to the views of people affected by cancer about cancer research: an example of participatory research in setting the cancer research agenda. Health Expect 2006;9:3-12.

5. Wells K, Jones L. Strategies for academic and clinician engagement in community-participatory partnered research. JAMA 2007;297:407-10.

6. Westfall JM, Fagnan LJ, Handley M, et al. Practicebased research is community engagement. J Am Board Fam Med 2009;22:423-7.

7. Ahmed SM, Palmero A-GS. Community engagement in research: frameworks for education and peer review. Am J Public Health 2010;100:1380-7.

8. Wallerstein N, Duran B. Community-based participatory research contributions to intervention research: the intersection of science and practice to improve health equity. Am J Public Health 2010; 100(Suppl 1):S40-6.

9. Westfall JM, VanVorst RF, Main DS, Herbert C. Community-based participatory research in practice-based research networks. Ann Fam Med 2006; 4(1):8-14.

10. Tapp H, Dulin M. The science of primary healthcare improvement: potential and use of communitybased participatory research by practice-based research networks for translation of research into practice. Exp Biol Med (Maywood) 2010;235:290-9.

11. Pace WD, Fagnan LJ, West DR. The Agency for Healthcare Research and Quality (AHRQ) Practicebased Research Network (PBRN) relationship: delivering on an opportunity, challenges, and future directions. J Am Board Fam Med 2011;24:489-92.

12. Mold JW, Peterson KA. Primary care practice-based research networks: working at the interface between research and quality improvement. Ann Fam Med 2005;3(Suppl 1):S12-20.

13. Boote JD, Twiddy M, Baird W, Birks Y, Clarke C, Beever D. Supporting public involvement in research design and grant development: a case study of a public involvement award scheme managed by a National Institute for Health Research (NIHR) Research Design Service (RDS). Health Expect 2013 Oct 1 [Epub ahead of print].

14. Williams R, Shelley B, Sussman A. The marriage of community-based participatory research and practice-based research networks: Can it work? - A Re- 
search Involving Outpatient Settings Network (RIOS Net) study. J Am Board Fam Med 2009;22: 428-35.

15. Domecq JP, Prutsky G, Elraiyah T, et al. Patient engagement in research: a systematic review. BMC Health Serv Res 2014;14:89.

16. Deverka PA, Lavallee DC, Desai PJ, al E. Stakeholder participation in comparative effectiveness research: defining a framework for effective engagement. J Comp Eff Res 2012;1:181-94.

17. Lavallee DC, Williams CJ, Tambor ES, Deverka PA. Stakeholder engagement in comparative effectiveness research: how will we measure success? J Comp Eff Res 2012;1:397-407.

18. Concannon TW, Meissner P, Grunbaum JA. A new taxonomy for stakeholder engagement in patientcentered outcomes research. J Gen Intern Med 2012: 27:985-91.

19. Frank L, Basch E, Selby JV. The PCORI perspective on patient-centered outcomes research. JAMA 2014; 312:1513-4.

20. Devoe JE, Sears A. The OCHIN community information network: bringing together community health centers, information technology, and data to support a patient-centered medical village. J Am Board Fam Med 2013;26:271-8.

21. Devoe JE, Gold R, Spofford M, et al. Developing a network of community health centers with a common electronic health record: description of the Safety Net West Practice-based Research Network
(SNW-PBRN). J Am Board Fam Med 2011;24:597604.

22. DeVoe JE, Likumahuwa S, Eiff MP, et al. Lessons learned and challenges ahead: report from the OCHIN Safety Net West practice-based research network (PBRN). J Am Board Fam Med 2012;25: 560-4.

23. Wright B, Martin GP. Mission, margin, and the role of consumer governance in decision-making at community health centers. J Health Care Poor Underserved 2014;25:930-47.

24. Angier H, Wiggins N, Gregg J, DeVoe J. Increasing the relevance of research to underserved communities: lessons learned from a retreat to engage community health workers with researchers. J Health Care Poor Underserved 2013;24:840-9.

25. Thomson R, Murtagh M, Khaw FM. Tensions in public health policy: patient engagement, evidencebased public health and health inequalities. Qual Saf Health Care 2005;14:398-400.

26. DeVoe JE, Gold R, Cottrell E, et al. The ADVANCE network: accelerating data value across a national community health center network. J Am Med Inform Assoc 2014;21:591-5.

27. DeVoe J, Angier H, Likumahuwa S, et al. Use of qualitative methods and user-centered design to develop customized health information technology tools within federally qualified health centers to keep children insured. J Ambul Care Manage 2014;37: 148-54. 


\section{Appendix1}

WE ARE OCHI N

\section{By-Laws: OCHIN Patient Engagement Panel (PEP)}

OCHIN Mission Statement and Work

OCHIN is a nonprofit healthcare innovation center designed to provide knowledge solutions that promote quality, affordable healthcare to all. Transforming healthcare to improve outcomes and reduce costs demands both innovation and collaboration. It takes individuals and communities working side-byside to design relevant and reasonably priced information technology and data solutions that can be shared across the healthcare continuum.

Patient Engagement Panel (PEP) Vision Statement

Patients offer important opinions and suggestions regarding healthcare, as well as experience and information from the patient perspective. The Patient Engagement Panel (PEP) will ensure that patient voices are heard. PEP members will work with policy makers, providers, and researchers to improve patients' healthcare experiences. PEP members will also help to shape the vision of the OCHIN PracticeBased Research Network (PBRN).

\section{Patient Engagement Panel Purpose}

PEP members will be asked to share their thoughts on their experiences with the healthcare system as regards:

- Research questions

- Changes to healthcare delivery and how it impacts patients

- How to best share information with the general public

- How to best recruit patients for studies

- Health technology

A member of the Patient Engagement Panel can expect to:

- Attend monthly meetings to share their thoughts, opinions and experiences about different healthcare topics.

- Provide input, as requested, on a variety of topics, such as patient communication materials, research proposals, recruitment models, changes to how clinics work, and sharing project findings.

Why Join the Patient Engagement Panel?

- Work together with healthcare information technology and researchers to build better research studies and help people live healthier lives.

- Gain insight and understanding of how medical research is done and what sort of research is taking place in doctor's offices.

- Help OCHIN present research findings to patients, caregivers and patient communities in an accessible, understandable and available manner by shaping the way people find out about these results.

Updated 140630

Continued 


\section{Recognition for participation:}

PEP members have the opportunity to receive gift cards in recognition of participating. You will receive gift cards based on the time you spend with us:

\begin{tabular}{|l|l|}
\hline \multicolumn{1}{|c|}{ Hours Spent Working with Us } & \multicolumn{1}{c|}{$\begin{array}{c}\text { Gift Card Amount } \\
\text { (To a Department Store of Your Choice) }\end{array}$} \\
\hline $1-3$ hours & $\$ 25$ \\
\hline $4-6$ hours & $\$ 50$ \\
\hline $7-9$ hours & $\$ 75$ \\
\hline $10-12$ hours & $\$ 100$ \\
\hline $13-15$ hours & $\$ 150$ \\
\hline
\end{tabular}

\section{Patient Engagement Panel Structure}

The PEP strives to include patients from all walks of life. PEP members may represent OCHIN member sites, other healthcare organizations, and/or community groups locally and nationally. The OCHIN Patient Engagement Coordinator will work with members to set agendas and schedule meetings. The PEP meets once a month for one and a half (1.5) hours at OCHIN headquarters in Portland, Oregon. Some members will participate via toll-free calls and screen-sharing technology.

\section{Norms and Expectations}

- Treat each other with dignity and respect

- Make every effort to come to meetings and events on time, either in person or through participation via screen-sharing technology

- No interrupting or "cross-talk"

- Refrain from cursing, swearing, or using derogatory language

How Do I Become Involved?

For more information, please contact [PEP Coordinator Name], Patient Engagement Coordinator at OCHIN, at [email], or by phone at [phone number].

\section{Signature of Member}

I have read and agree with the Patient Engagement Panel by-laws and have signed and printed below.

Signature of patient, or legal representative

Printed name of patient, or patient's legal representative

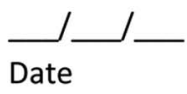

Legal representative's relationship to the patient 